\title{
Microstructure and Mechanical Properties of Medical Magnesium Alloy Fabricated by Unequal Channel Angular Pressing
}

\author{
Xiaoping Luo, Mingang Zhang, Daqin Fang, Yaosheng Chai \\ School of Materials Science and Engineering, Taiyuan University of Science and Technology, Taiyuan, China. \\ Email:am_lab@yeah.net \\ Received January $16^{\text {th }}, 2013$; revised March $1^{\text {st }}, 2013$; accepted April $3^{\text {rd }}, 2013$ \\ Copyright (C) 2013 Xiaoping Luo et al. This is an open access article distributed under the Creative Commons Attribution License, \\ which permits unrestricted use, distribution, and reproduction in any medium, provided the original work is properly cited.
}

\begin{abstract}
A new unequal channel angular pressing (UCAP) procedure is proposed for ultrafine-grained metals and alloys. The microstructures and mechanical properties of $\mathrm{Mg}-5.8 \mathrm{Zn}-1.2 \mathrm{Y}-0.7 \mathrm{Zr}$ alloys subjected to unequal channel angular pressing (UCAP) are investigated. It is found that the optimum condition in UCAPed alloy is obtained at $523 \mathrm{~K}$ with a largest elongation to failure of $13.1 \%$ and ultimate tensile strength of $\sim 400 \mathrm{MPa}$. Microstructural observations show that the grain size is refined to $\sim 1.0 \mu \mathrm{m}$ during UCAP. The probable mechanisms for these high mechanical properties are attributed to grain size and destroyed secondary phase strengthening effects and fine precipitates formed during pressing at high temperature by severe shear and plastic deformation.
\end{abstract}

Keywords: Mg-Zn-Y-Zr Magnesium Alloy; Unequal Channel Angular Pressing; Microstructure; Mechanical Property

\section{Introduction}

During the last decade, equal-channel angular pressing (ECAP) has attracted considerable attention as a widely known procedure for the fabrication of ultrafine-grained metals and alloys [1-3]. As is known, the mechanical and physical properties of metallic materials are determined by several factors, and the average grain size of the material generally plays a very significant role. To convert a coarse-grained solid into a material with ultrafine grains by ECAP, metals were subjected to large deformation under high applied pressures in attempts to improve their mechanical properties. However, the ECAP process as currently used in the laboratory is labor-intensive, low efficiency and high in production cost because it requires many extrusion passes to achieve the desired grain refinement. Accordingly, it is now recognized that any extensive industrial application will require the development of some form of efficient continuous processing technique. Therefore, in this paper we propose a new procedure, unequal channel angular pressing (UACP).

Magnesium-based alloys, being biomedical metallic materials, have great potential for application in bone fixed parts due to their high strength-to-density ratio and biocompatibility [4-6]. However, applications of the close- packed hexagonal structure of magnesium alloys are still limited because of low mechanical properties [7,8]. Therefore, extensive efforts have been focused on alloying and plastic processing to develop magnesium alloys with good mechanical properties. Among many possibilities, addition of $\mathrm{Y}$ element can provide with high strength and small amount of $\mathrm{Zr}$ may provide finer solidified microstructure in the $\mathrm{Mg}-\mathrm{Zn}$ alloy, as reported effects of yttrium on the microstructure and mechanical properties of Mg-Zn-Y-Zr alloys, etc. [9-11].

In recent years, the interest in Mg-Zn-Y-Zr alloys containing quasicrystal I-phase [12-14] as the secondary phase, which formed upon solidification and has many good properties such as high hardness, thermal stability, etc., has been growing, because these alloys posses improved yield and ultimate tensile strengths after going through thermomechanical processing [15-17] such as hot compression, hot extrusion, etc. In these studies, mechanical properties at room temperature, superplastic behaviors at high temperatures, precipitation behavior during thermo-mechanical treatment, etc., have been investtigated.

Up to now there have been limited studies addressing the changes on microstructural and mechanical properties of Mg-Zn-Y-Zr alloys during UACP processes. To im- 
prove the strength and ductility of $\mathrm{Mg}-\mathrm{Zn}-\mathrm{Y}-\mathrm{Zr}$ alloys further in the present investigation, UCAP processing is carried out on Mg-5.8Zn-1.2Y-0.7Zr magnesium alloy at different temperature.

\section{Experimental}

The materials used in the present study were prepared from pure magnesium (99.9\%), pure Zn (99.99\%), Mg$25 \% \mathrm{Y}$ and $\mathrm{Mg}-33 \% \mathrm{Zr}$ master alloys by electric crucible melting under the protection of a mixed gas atmosphere of $99.5 \% \mathrm{CO}_{2}$ and $0.5 \% \mathrm{SF}_{6}$ (vol\%). The melted $\mathrm{Mg}$ $5.8 \mathrm{Zn}-1.2 \mathrm{Y}-0.7 \mathrm{Zr}$ alloy was cast into a permanent mould and machined to dimensions of $40 \times 40 \times 20 \mathrm{~mm}$ using spark cutting and then pressed in an UCAP die (as shown in Figure 1) before being extruded into rods, $10 \times 10$ $\mathrm{mm}$, at different temperatures $(473-673 \mathrm{~K})$ with an extrusion ratio of 16 . The microstructures of both the ascast and UCAP processed alloys were observed with an optical microscope (VHX-600E) and scanning electron microscope (Hitachi S-4800) and a JEM-2010 transmission electron microscope (TEM). Phase analyses were performed with a PANalytica X' X-ray diffractometer (XRD). The samples were ground and polished using standard metallography procedures, and the untreated alloys were etched with a mixture of $1 \mathrm{~mL}$ nitric acid and $24 \mathrm{~mL}$ ethylene glycol. UCAP processed alloys were etched with an etchant comprising $1 \mathrm{~mL}$ oxalic acid, 1 $\mathrm{mL}$ nitric acid and $98 \mathrm{~mL}$ water. TEM samples were prepared by slicing plates perpendicular to the long axis of the billet. Final thinning was performed by twin-jet electropolishing in a solution of $10 \% \mathrm{HClO}_{4}$ and $90 \%$ $\mathrm{C}_{2} \mathrm{H}_{5} \mathrm{OH}$. Tensile tests were carried out on an MTS universal testing machine at a nominal strain rate of 0.4 $\mathrm{mm} / \mathrm{s}$ at room temperature, dog-bone shape tensile specimens with cross-section of $4 \times 2 \mathrm{~mm}$ and gauge length of $32 \mathrm{~mm}$ machined from the UCAP processed samples, with their tensile axes lying parallel to the pressing direction.

\section{Results and Discussion}

\subsection{Microstructures}

Figure 2 shows SEM images of the Mg-5.8Zn-1.2Y$0.7 \mathrm{Zr}$ cast alloy. As seen in Figure 2(a), there are two distinct regions present, which appear as white and grey in the image. Figures $\mathbf{2}\left(\mathbf{a}_{1}\right)$ and $\left(\mathbf{a}_{2}\right)$ are the EDS analysis results at test points 1 (grey region) and 2 (white region), respectively in Figure 2(a). Test point 1 is grey $\alpha-\mathrm{Mg}$ solid solution matrix, as shown by its very high $\mathrm{Mg}$ content, and small $\mathrm{Zn}$ content; this implies that not much $\mathrm{Zn}$ was dissolved into the Mg during melting. The EDS analysis also shows that the white region (Figure 2( $\left.\mathbf{a}_{2}\right)$, test point 2) contains three elements. The enlarged image of

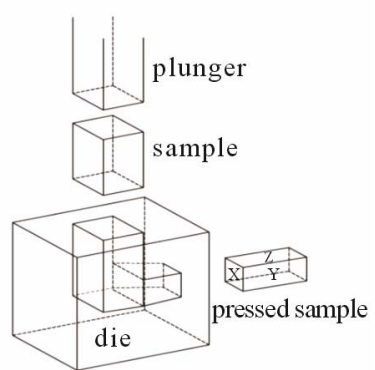

Figure 1. The sketch map of the UCAP die.

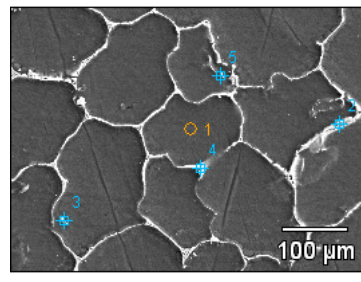

(a)

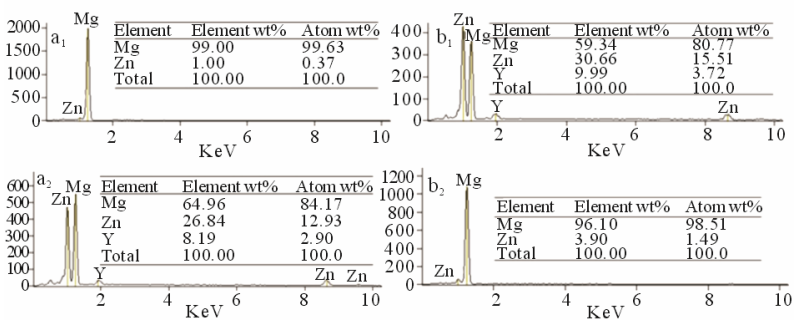

(c)

Figure 2. SEM and EDS of Mg-5.8Zn-1.2Y-0.7Zr magnesium alloys before UCAP.

the grain boundary, Figure 2(b), shows that the grain boundary has a layered microstructure. The EDS spectra of test points 1 and 2 in Figure 2(b) show that the microstructure is a mixture of $\alpha-\mathrm{Mg}$ matrix and some ternary intermetallic compounds. A small amount of $\mathrm{Zn}$ has been dissolved into the $\alpha-\mathrm{Mg}$ interstitial matrix solution, and the $\mathrm{Y}$ has segregated in the ternary compounds. The Mg$5.8 \mathrm{Zn}-1.2 \mathrm{Y}-0.7 \mathrm{Zr}$ as-cast alloy consists of $\alpha-\mathrm{Mg}$, with coarse grains, $\sim 110 \mu \mathrm{m}$, forming a net-like structure, and the secondary phase or phases at the grain boundaries. Based on XRD analysis (as shown in Figure 3) and microstructure observation, it can be determined that the secondary phases in the as-cast $\mathrm{Mg}-5.8 \mathrm{Zn}-1.2 \mathrm{Y}-0.7 \mathrm{Zr}$ alloy are $\mathrm{Mg}_{3} \mathrm{Zn}_{6} \mathrm{Y}$ (I-phase) and $\mathrm{Mg}_{3} \mathrm{Zn}_{3} \mathrm{Y}_{2}$ (W-phase).

Figure 4 shows the microstructure of Mg-5.8Zn-1.2Y$0.7 \mathrm{Zr}$ alloy after UCAP of three orthogonal surfaces representing the $\mathrm{X}, \mathrm{Y}$, and $\mathrm{Z}$ planes as defined in Figure 1. Inspection of the $X$ plane in Figure 4(a) shows that the grains which were initially equiaxed have become elongated along the $\mathrm{Y}$ direction and flattened in the $\mathrm{Z}$ direction. In addition, slip is visible within the elongated grains lying approximately parallel to the $\mathrm{Z}$ direction. On the $\mathrm{Z}$ 


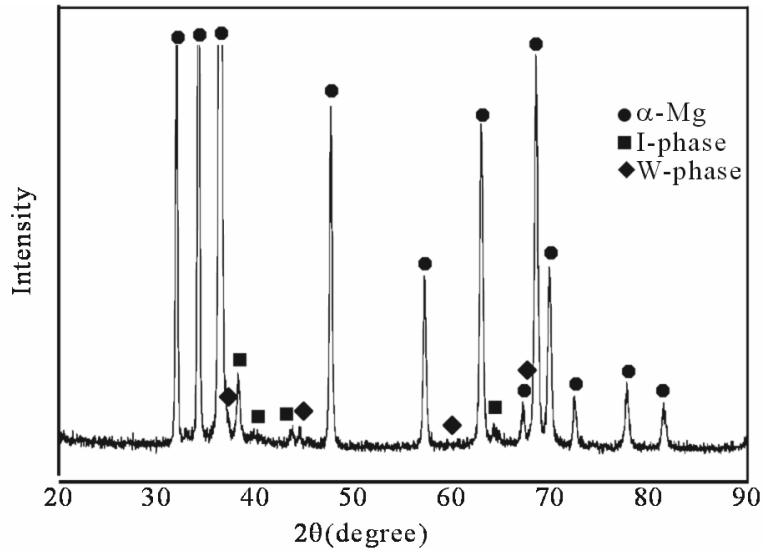

Figure 3. X-ray diffraction pattern of the Mg-5.8Zn-1.2Y$0.7 \mathrm{Zr}$ alloy before UCAP.

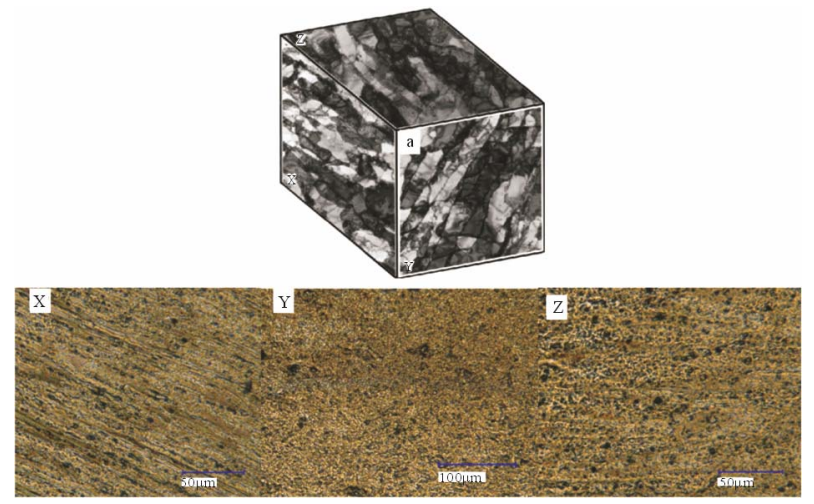

Figure 4. Optical microstructure of Mg-5.8Zn-1.2Y-0.7Zr alloy after UCAP at $523 \mathrm{~K}$.

plane, the grains are elongated in an inclined direction, and on the $\mathrm{Y}$ plane the grains remain reasonably equiaxed, reduced from their initial size, and there is some slip parallel to the $\mathrm{Z}$ direction. It is clear from these photomicrographs that the coarse-grains have become fragmented by the high pressure imposed and sheared during UCAP. The microstructure shows the presence of small grains of $\sim 1-3 \mu \mathrm{m}$ diameters together with comparatively coarse grains. Some grain sizes are too small to be distinguished by optical microscopy. At low processing temperature (Figures $4(\mathrm{x}-\mathrm{z})$ ), microstructures are mainly composed of fine recrystallized grains. Moreover, some elongated and unrecrystallised grains along extrusion direction are also observed. These elongated and unrecrystallised grains have high dislocation density. In contrast, with increasing processing temperature, more recrystallized grains appear in microstructures. The increase of processing temperature results in grain growth, on the other hand, coordinated movement among grains is improved because elongated grains are replaced by equiaxed and recrystallised grains. A closer investigation using SEM revealed that the grain size of the UCAP sam- ple is $0.8 \mathrm{um}$. Figure 5 shows the SEM image of the UCAPed alloy. Secondary phase of the alloy are moved away from grain boundaries and destroyed into smaller particles with irregular shape by UCAP.

To check this possibility, Figure 6 shows the DSC results of the before and after UCAP alloys during the heating process where the material was subjected to a heating rate of $10 \mathrm{~K} \cdot \mathrm{min}^{-1}$. The first endothermic peak appeared at about $771 \mathrm{~K}$ for before UCAP alloy and 793 $\mathrm{K}$ for after UCAP alloys. This peak corresponds to the melting temperature of eutectic phase. The eutectic temperature of UCAP alloys is much higher than the eutectic temperature of as-cast alloy, showing that under high temperature and severe plastic deformation, UCAP refined grain that can lead to the composition of the matrix alloy changed, part of the I-phase is dissolved into the $\alpha-\mathrm{Mg}$ and released $\mathrm{Zn}$ and formed $\mathrm{W}$-phase in the region with a higher concentration and phase transition temperature significantly improved. The lower eutectic temperature of as-cast alloy is much higher than the eutectic temperature of Mg-Zn binary alloy $(613 \mathrm{~K})$. It can be inferred that the addition of yttrium can greatly increase the eutectic temperature compared to $\mathrm{Mg}$ - $\mathrm{Zn}$ binary alloy. Based on the DSC curves and microstructural examinations, it is concluded that significant grain refinement and breakup of the secondary phases and their dispersive distribution in the Mg matrix by the UCAP severe plastic deformation contributes to the high melting temperature.

Figure 7 shows the TEM morphology and selected area diffraction patterns (SADP). The SADP are taken from the large particles in the UCAP treated alloy, and allow these particles to be identified as I-phase and Wphase, which confirms the XRD results for the as-cast alloy. The particle which has a diffraction pattern showing five-fold symmetry can be identified as I-phase.

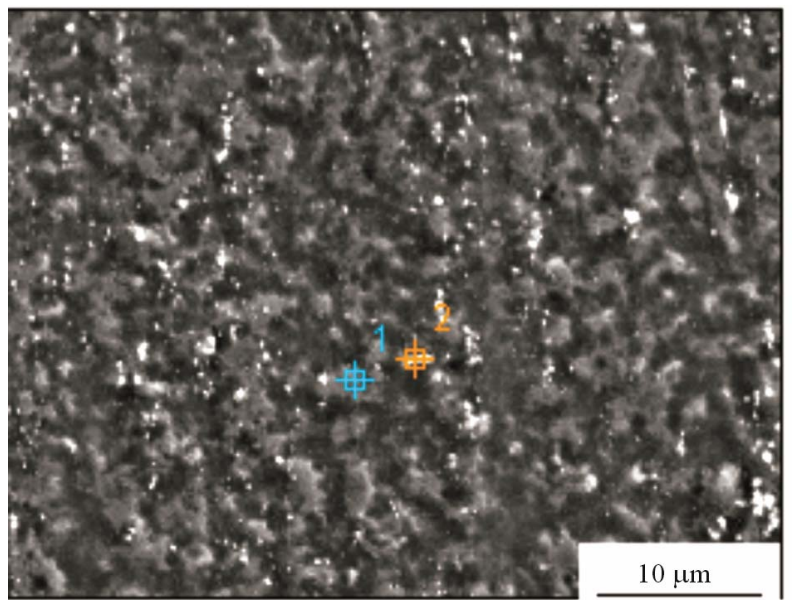

Figure 5. SEM image of the Mg-Zn-Y-Zr alloy after UCAP at $523 \mathrm{~K}$. 


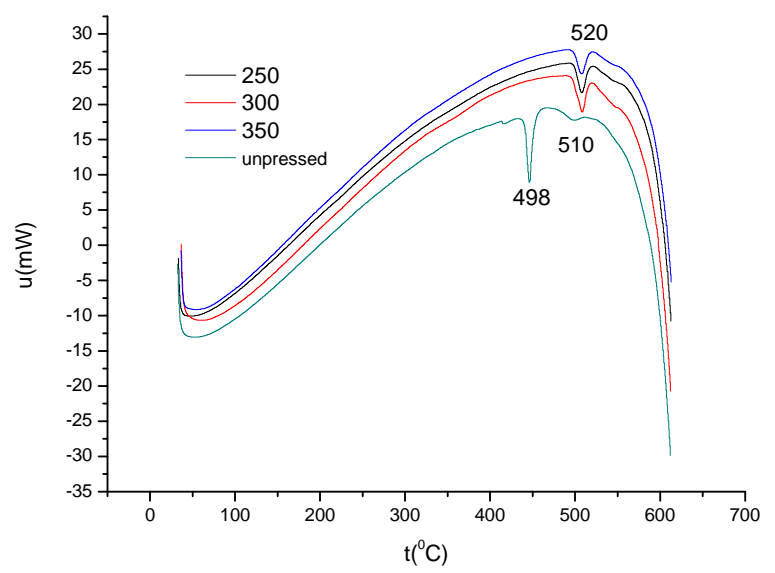

Figure 6. DSC of Mg-5.8Zn-1.2Y-0.7Zr before and after UCAPed alloy.

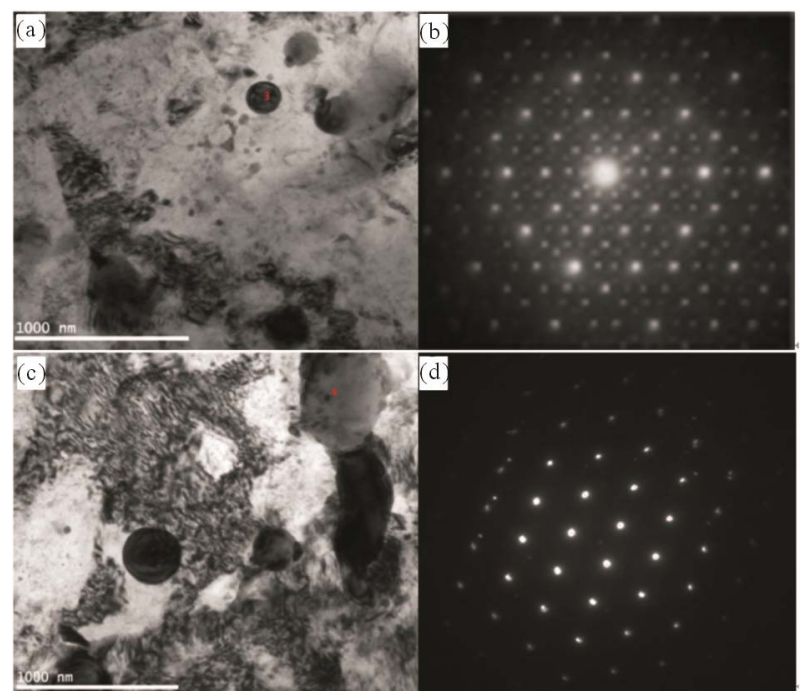

Figure 7. TEM images of large destroyed particles in the UCAPed Mg-5.8Zn-1.2Y-0.7Zr alloy at $573 \mathrm{~K}$ : (a) I-phase; (b) The selected area diffraction (SAD) patterns of I-phase; (c) W-phase; (d) The selected area diffraction (SAD) patterns of $W$-phase.

\subsection{Mechanical Properties}

The small grain sizes and high defect densities inherent in materials processed by UCAP lead to much higher mechanical properties than those of their coarse-grained counterparts. Table 1 shows the mechanical properties of the alloys UCAP processed at different temperatures. UCAP treatment has produced outstanding improvement in both strength and ductility-related characteristics. The mechanical properties depend strongly on the processing temperature. There was an obvious decrease in the yield strength (YS) and the ultimate tensile strength (UTS) for the sample processed at $673 \mathrm{~K}$ compared with the sample processed at $473 \mathrm{~K}$. The best combination of both high yield strength and ultimate tensile strength was found
Table 1. Mechanical properties of Mg-5.8Zn-1.2Y-0.7Zr magnesium alloys after UCAP.

\begin{tabular}{lccccc}
\hline UCAP temperature (K) & 473 & 523 & 573 & 623 & 673 \\
Yield strength (Mpa) & 330 & 326 & 312 & 302 & 285 \\
Tensile strength (Mpa) & 395 & 400 & 390 & 385 & 350 \\
Elongation (\%) & 12.8 & 13.1 & 13.6 & 12.1 & 14.2 \\
\hline
\end{tabular}

at $523 \mathrm{~K}$. The increase in the processing temperature provides a similar effect to that reported in previous studies.

\section{Conclusion}

Mg-5.8Zn-1.2Y-0.7Zr alloy consists of $\alpha-\mathrm{Mg}, \mathrm{Mg}_{3} \mathrm{Zn}_{6} \mathrm{Y}$ and $\mathrm{Mg}_{3} \mathrm{Zn}_{3} \mathrm{Y}_{2}$ phases in the unpressed condition. The microstructure of the cast alloy in the homogenized state was coarse-grained with an average grain size of about $110 \mu \mathrm{m}$, processing by UCAP produced considerable grain refinement. $\mathrm{Mg}_{3} \mathrm{Zn}_{6} \mathrm{Y}$ phases were destroyed into small particles. These particles played a strengthening role in the UACPed alloy and led to a final ultimate tensile strength of $\sim 400 \mathrm{MPa}$ and sufficient ductility of $13.1 \%$.

\section{Acknowledgements}

The study was financially supported by both the Key Science and Technology Program of Shanxi Province, China (No. 20090322007), and the project of innovation of Shanxi Province Postgraduates (No. 20100392).

\section{REFERENCES}

[1] S. W. Xu, M. Y. Zheng, X. G. Qiao, W. M. Gan, K. Wu, S. Kamado and Y. Kojima, "Microstructure and Tensile Properties of Mg-Zn-Y-Zr Alloy Containing Quasicrystal Phase Processed by Equal Channel Angular Pressing," Key Engineering Materials, Vol. 350-358, 2007, pp. 595598.

[2] M. Y. Zheng, S. W. Xu, X. G. Qiao, K. Wu, S. Kamado and Y. Kojima, "Compressive Deformation of Mg-Zn-YZr Alloy Processed by Equal Channel Angular Pressing," Materials Science and Engineering: A, Vol. 483-484, 2008, pp. 564-567.

[3] M. Y. Zheng, S. W. Xu, K. Wu, S. Kamado and Y. Kojima, "Superplasticity of Mg-Zn-Y Alloy Containing Quasicrystal Phase Processed by Equal Channel Angular Pressing," Materials Letters, Vol. 61, 2007, pp. 4406-4408.

[4] B. Zberg, P. J. Uggowitzer and J. F. Loeffl, "Mg-Zn-Ca Glasses without Clinically Observable Hydrogen Evolution for Biodegradable Implants," Nature Materials, Vol. 8, No. 11, 2009, pp. 887-891.

[5] L. Hench and J. M. Polak, "Third-Generation Biomedical Materials," Science, Vol. 5557, No. 295, 2008, pp. 10141027. 
[6] R. C. Zeng, W. Dietzel, F. Wittel, N. Hort and C. Blawert, "Progress and Challenge for Magnesium Alloys as Biomaterials," Advanced Engineering Materials, Vol. 10, No. 8, 2008, pp. 3-14.

[7] Z. Yang, J. P. Li, J. X. Zhang, G. W. Lorimer and J. Robson, "Review on Research and Development of Magnesium Alloys," Acta Metallurgica Sinica, Vol. 21, No. 5, 2008, pp. 313-328.

[8] Z. H. Chen, W. J. Xia and H.-G. Yan, "Wrought Magnesium Alloy," Chemical Industry Press, Beijing, 2005, pp. 3-6. (In Chinese)

[9] Y. Zhang, X. Q. Zeng, L. F. Liu, L. Chen and H. T. Zhou, "Effects of Yttrium on Microstructure and Mechanical Properties of Hot-Extruded Mg-Zn-Y-Zr Alloys," Materials Science and Engineering: A, Vol. 373, No. 1-2, 2004, pp. 320-327.

[10] J. Y. Lee, D. H. Kim and H. K. Lim, "Effects of Zn/Y Ratio on Microstructure and Mechanical Properties of Mg-Zn-Y Alloy," Materials Letters, Vol. 59, No. 5, 2005, pp. 3801-3805.

[11] T. Homma, C. L. Mendis, K. Hono and S. Kamado, "Effect of $\mathrm{Zr}$ Addition on the Mechanical Properties of As-Extruded Mg-Zn-Ca-Zr Alloys," Materials Science and Engineering: A, Vol. 527, No. 9, 2010, pp. 23562362.

[12] D. H. Bae, M. H. Lee, K. T. Kim and W. T. Kim, “Ap- plication of Quasicrystalline Particles as a Strengthening Phase in Mg-Zn-Y Alloys," Journal of Alloys and Compounds, Vol. 445, No. 3, 2002, pp. 445-450.

[13] D. H. Bae, Y. Kim and I. J. Kim, "Thermally Stable Quasicrystalline Phase in a Super Plastic Mg-Zn-Y-Zr," Materials Letters, Vol. 60, 2006, pp. 2190-2193.

[14] Y. Lee, H. K. Lim, D. H. Kim, W. T. Kim and D. H. Jim, "Effect of Icosahedra Phase Particles on the Texture Evolution in Mg-Zn-Y Alloys," Materials Science and Engineering: A, Vol. 491, No. 1-2, 2008, pp. 349-354.

[15] T. Peng, Q. D. Wang, M. P. Lu, J. Zheng and J. B. Lin, "An Optimization Approach for Hot Compaction Technology of Mg-10Gd-2Y-0.5Zr Alloy during Solid-State Recycling," Power Technology, Vol. 194, 2009, pp. 142 148.

[16] L. H. Wen, Z. S. Ji and X. L. Li, "Effect of Extrusion Ratio on Microstructure and Mechanical Properties of Mg-Nd-Zn-Zr Alloys Prepared by a Solid Recycling Process," Journal of Materials Processing Technology, Vol. 209, 2009, pp. 5319-5324.

[17] S. W. Xu, M. Y. Zheng, S. Kamado, K. Wu, G. J. Wang and X. Y. Lv, "Dynamic Microstructural Changes during Hot Extrusion and Mechanical Properties of a Mg-5.0 Zn-0.9 Y-0.16Zr (wt\%) Alloy," Materials Science and Engineering: A, Vol. 528, No. 12, 2011, pp. 4055-4064. 